\title{
The Influence of the Big Five Personality Traits on Burnout in Medical Doctors
}

\author{
Dr. Anita Sharma ${ }^{1}$, Associate Professor and HOD \& Neelabh Kashyap ${ }^{1}$, Research Scholar \\ ${ }^{1}$ Department of Psychology, HPU, Shimla, India \\ Correspondence: Neelabh Kashyap, Research Scholar, Department of Psychology, HPU, Shimla, India
}

Received: August 21, 2017

Accepted: September 25, $201 \quad$ Online Published: October 10, 2017

doi:10.5539/ijps.v9n4p13

URL: http://doi.org/10.5539/ijps.v9n4p13

\begin{abstract}
The objective of present study was to investigate the relationship between the Big Five personality factors and burnout in medical doctors. The sample comprised of 100 doctors (50 males and 50 females). Results of the study revealed that personality factors explained significant amount of variance in both the males' and females' sample. In females' sample, agreeableness explained the maximum variance of $26 \%\left(\mathrm{r}=-.507^{* *}, \mathrm{p}<.01\right)$ in depersonalization, extraversion explained $12 \%\left(\mathrm{r}=-.355^{*}, \mathrm{p}<.05\right)$ of variance in emotional exhaustion, conscientiousness explained $11 \%\left(\mathrm{r}=-.351^{*}, \mathrm{p}<.05\right)$ of variance in reduced personal accomplishment and neuroticism explained 9\% ( $\mathrm{r}=.098)$ of variance in reduced personal accomplishment. In males' sample, extraversion turned out to be the best predictor of emotional exhaustion and explained $11 \%\left(\mathrm{r}=-.385^{* *}, \mathrm{p}<.01\right)$ of variance in the said variable and openness explained about $10 \%\left(\mathrm{r}=-.319^{*}, \mathrm{p}<.05\right)$ of variance in depersonalization. Overall these personality factors have explained $58 \%$ of variance in females' sample and $21 \%$ of variance in males' sample.
\end{abstract}

Keywords: burnout, emotional exhaustion, depersonalization, reduced personal accomplishment, Big Five personality traits

\section{Introduction}

Burnout is usually defined as a psychological syndrome characterized by emotional exhaustion, depersonalization and reduced personal accomplishment. It arises out as a reaction to continuous stress at workplace (Maslach, Jackson, \& Leiter, 1996). While it is possible for people of almost all professions to get burned out because of continuously being exposed to stress inherent in their jobs, "helping" profession of lawyers, healthcare professionals (such as nurses and doctors), teachers, social workers, etc., are more likely to get burned out. Usually, healthcare settings (like hospitals) can be seen as having two broad groups of people - one who gives care such as nurses or doctors and other who receives it. The relationship between receivers of care (or patients) and providers of care (such as doctors) is of such nature that, at times, it demands too much emotional energy from the providers of care. Sometimes, while fulfilling the demands of their profession and taking care of their patients, doctors suffer emotional exhaustion, depersonalization and reduced personal accomplishment, the three components of burnout syndrome. Being emotionally exhausted implies the feelings of completely getting drained out of emotional energy. Depersonalization means building up of an overall cynical and negative outlook towards the receiver of care. An inclination towards negative evaluation of one's work with care recipients and simultaneous feelings of inadequacy, characterizes lack of personal accomplishment (Maslach, 1982).

Researchers like Von Kanel (2008), Peterson, Demerouti, Bergstrom, Samuelson, Åsberg and Nygren (2008) and more have suggested that illnesses like anxiety, chronic fatigue syndrome, fibromyalgia, adjustment disorder, depression, diabetes and cardiovascular diseases are associated with burnout or may follow it. So burnout is a matter of serious concern whenever well being of doctors is taken into account. Besides diseases, burnout is also associated with heavy decline in level of performance at work. For hospitals this implies that the quality of healthcare they provide is severely affected when a significant number of the healthcare professionals are in grip of burnout. Williams, Manwell, Konrad and Linzer (2007) have shown that incidence of errors and mistakes by doctors and physicians increases a lot when these professionals are in the grip of burnout and as a result less than optimal level of care gets frequently delivered in such settings. In this study, the sample that was suffering from burnout was constituted, by almost $40 \%$, by angry and irritated doctors who often used to get furious and 
irritated while dealing with patients and colleagues. Also, in the same sample, $7 \%$ committed serious medical mistakes and errors.

When exploring the causes of burnout, many studies have pointed towards "high workload" as one of the most important causes. In their study of a multidisciplinary team (which included doctors, nurses, etc.) responsible for dealing with cases of cancer, Sehlen, Vordermark, Schäfer, Herschbach, Bayerl, Pigorsch and Geinitz (2009) pointed out that when work at office, time-pressure and overall workload becomes excessive, job related stress also increases. McMurray, Linzer, Konrad, Douglas, Shugerman and Nelson (2000) came up with a remarkable finding in their study on work life of women physicians that strengthened the argument that workload and burnout are related. They concluded, from their study, that the chances of getting burned out increased by $12-15 \%$ for every 5 additional hours spent on the job. Besides workload, absence of rewards is also associated with burnout. When rewards are absent, a certain type of dissatisfaction is caused in an employee. This dissatisfaction leads to a cynical attitude and this leads to burnout (Maslach \& Leiter, 1997). Similarly, Sehlen et al. (2009), in their study of a cancer team, found that an absence or lack of incentive or reward for working overtime is linked to burnout.

Some researchers like Mc Vicar (2003), Marine, Ruotsalainen, Serra and Verbeek (2006) have explored the specific type of stressors present in hospitals and other healthcare settings. They found that some of the most severe forms of stressors are inherent in healthcare settings. These include huge uncertainties about treatment of patients, inadequate or even complete absence of social support, high workload and time pressure, etc. Also doctors are surrounded by people who are in pain, patients who are suffering, people whose medical condition has reached a stage that they will, most probably, die, relatives of dead patients, etc. All these together create an environment that's "charged up" emotionally and doctors are required to use a lot of their emotional energy and resources in order to be effective in their jobs.

Every individual has some characteristics which make that person unique in a way. Attitude towards job, demographic features (like age, etc.), personality, etc., are all examples of such characteristics. Researchers have found that such characteristics can also affect burnout. For example there have been studies which point to the fact that age also plays a big role in development and experience of burnout among doctors. Peisah, Latif, Wilhelm and Williams (2009) found in their study that older and more experienced doctors experienced lesser burnout than doctors who are new in their careers and are young. The lessons learned after many years of training and practice is biggest reason for this, according to the researchers. Similarly, Kizilci, Sevgi, Vesile and Emin (2012) explored the role of personality in burnout among nurses and found that personality plays a big role in burnout.

Personality has been one of the prominent areas of study and researches in psychology and several studies have indeed explored the area of personality and burnout. Since this paper intends to explore the influence of personality on burnout, it is necessary to have a look at previous research done in the area of personality and burnout. In one study, Zellars, Kelly, Perrewe and Hochwarter (2000) chose employees working in healthcare setting as research participants. Their study had three major findings. First was that "openness to experience" (or simply openness), one of the five factors of the "Big Five" personality traits, was positively associated with personal accomplishment. High scorers on openness had higher level of personal accomplishment. Second major finding was that neuroticism was a predictor of both emotional exhaustion and depersonalization. Third, extraversion, agreeableness and openness were negatively associated with depersonalization. Similarly, Deary, Blenkin, Agius, Endler, Zealley and Wood (1996) also found a positive relationship between openness and personal accomplishment among consultant doctors. Also, studying the relationship between occupational burnout and personality traits of Turkish teachers, Unaldi, Bardakci, Dolas and Arpaci (2013) found openness was negatively correlated with depersonalization and positively with personal accomplishment.

In another study, with an aim to examine the relationship between the big five personality dimensions of conscientiousness and neuroticism with burnout in healthcare staff of hospitals, Azeem (2013) requested 120 respondents from 8 big hospitals to participate in his study. Maslach's Burnout Inventory (MBI) and Big-Five Inventory were used. Results of his study revealed that conscientiousness was negatively and significantly related to all three dimensions of burnout. Neuroticism was found to be positively and significantly related to all three dimensions of burnout. Multiple regression analysis was used to find the best predictor of burnout in the sample. Results showed that conscientiousness significantly predicted all the dimensions of burnout. Similarly, LePine, LePine, and Jackson (2004) found a negative correlation between conscientiousness and emotional exhaustion in a study of 696 learners. 
Studying job-related stress and personal achievement among consultant doctors, Deary, Blenkin, Agius, Endler, Zealley and Wood (1996) reported that agreeableness is negatively related to depersonalization. Agreeable people co-operate. The co-operative nature of agreeable individuals might be a big factor in achieving success in occupations where teamwork and customer service are relevant. So these people can be expected to have good level of personal accomplishment (Judge, Higgins, Thoresen, \& Barrick, 1999). Examining job stressors, personality and burnout in primary school teachers, Kokkinos (2007) found that emotional exhaustion and depersonalization were negatively associated with agreeableness. Similarly, Cañadas-De la Fuente, Vargas, San Luis, García, Cañadas and De la Fuente (2015) also found that depersonalization was negatively correlated with agreeableness.

Studying burnout levels and personality traits in Turkish architectural students, Celik and Oral (2013) found in their study that emotional exhaustion was often observed together with "neurotic" personality traits of students. More researchers (e.g., Deary et al., 1996; and Zellars et al., 2000) have studied the relationship between neuroticism and burnout. They have also shown that individuals who are high in neuroticism are more likely to report feelings of emotional exhaustion. In addition to suffering from the chronic state of getting emotionally and psychologically drained, individuals scoring high in neuroticism, tend to report lower levels of personal achievement as well. Individuals high in neuroticism have also been found to report higher depersonalization. In healthcare settings this could mean development of a negative attitude towards patients and reducing them to a somewhat subhuman level. In a study of intensive-care nursing staff, Buhler and Land (2003) found that individuals who were higher in neuroticism experienced higher levels of both emotional exhaustion and depersonalization. Also Takemura, Hasegawa and Tamura (2015) studied burnout syndrome and personality in Japanese students and found that higher the neuroticism, higher was depersonalization.

Keeping in mind the findings of above mentioned studies, the present study is an attempt to explore the role of big five personality factors in burnout among doctors. It is also an attempt at testing the above formulations to see the strength of correlation and exact variance explained by the correlates.

\section{Method}

\subsection{Sample}

The sample for the present study comprised of 100 male and female doctors (physicians and surgeons across different specialties-pediatrician, gynecologists, cardiologists, etc.) of the age group 27-45 (i.e., who are in the middle or beginning of their careers) working in "big and busy" hospitals. They were selected on the basis of convenient sampling from different hospitals in Shimla and Delhi.

\subsection{Design}

Correlational design was used to see the association between Big Five and burnout. Further, regression analysis was carried out separately for both the samples to find out the best set of predictors of burnout (Emotional exhaustion, Depersonalization and Reduced personal accomplishment).

\subsection{Tools}

\subsubsection{Maslach Burnout Inventory (MBI by Maslach \& Jackson, 1986)}

To measure burnout, Maslach Burnout Inventory was used in the present study. It consists of 22 items that describe feelings connected with work. This inventory measures three components of burnout. Nine items in the inventory measure emotional exhaustion, five items measure depersonalization and eight items measure reduced professional (or personal) accomplishment. Burnout is indicated by higher scores on the emotional exhaustion and depersonalization scales and lower scores on the professional accomplishment. The emotional exhaustion scale measures the degree to which respondents feel emotionally drained. The depersonalization scale measures the degree or level to which respondents show a "less than human" attitude towards recipients of care. The reduced personal accomplishment scale measures participant's feelings of competence and success in their jobs. For each item, participants assessed the frequency of their feelings on a 7 point scale $(0-6$ where 0 indicated never and 6 indicated everyday). MBI has very good psychometric properties.

\subsubsection{Big Five Inventory (BFI by Benet-Martınez \& John, 1998)}

Big Five Inventory (BFI), developed by Benet-Martinez and John (1998), was used for measuring five-factor personality dimensions. In this inventory the most typical traits of each of the big five dimensions are assessed by short phrases. The inventory has 44 items that provides assessment of following five personality dimensions: extraversion, agreeableness, conscientiousness, neuroticism and openness. Self report ratings for each item are made on a scale from 1 (disagree strongly) to 5 (agree strongly). BFI has good psychometric properties. In U.S. 
and Canadian samples, the alpha reliabilities of the BFI scales typically range from 0.75 to 0.90 . 3-month test-retest reliabilities range from .80 to .90 , with a mean of .85 . Previous studies have shown usefulness of the inventory for cross-language and cross-cultural research (Benet-Martınez \& John, 1998).

\section{Results}

Results of the present study revealed that in females' sample (Table1), emotional exhaustion, the first component of burnout, correlated significantly and negatively with openness $\left(\mathrm{r}=-.292^{*}, \mathrm{p}<.05\right)$ and extraversion $\left(\mathrm{r}=-.355^{*}\right.$, $\mathrm{p}<.05$ ). In regression analysis only extraversion emerged as a significant predictor of emotional exhaustion and explained about $12 \%$ of variance (Table 3). Depersonalization, the second component of burnout, correlated negatively and significantly with agreeableness $\left(\mathrm{r}=-.507^{* *}, \mathrm{p}<.01\right)$ and openness $\left(\mathrm{r}=-.319^{*}, \mathrm{p}<.05\right)$. In regression analysis, only agreeableness emerged as a significant predictor of depersonalization and explained $26 \%$ of variance. Results have also shown that reduced personal accomplishment, the third component of burnout, correlated negatively and significantly with conscientiousness $\left(\mathrm{r}=-.351^{*}, \mathrm{p}<.05\right)$. In regression analysis conscientiousness emerged as a significant predictor of reduced personal accomplishment and explained $11 \%$ of variance (Table 3).

In males' sample (Table 2), emotional exhaustion correlated negatively and significantly with extraversion $\left(\mathrm{r}=-.385^{* *}, \mathrm{p}<.01\right)$ but positively and significantly with openness $\left(\mathrm{r}=.287^{*}, \mathrm{p}<.05\right)$. In regression analysis extraversion emerged as a significant predictor of emotional exhaustion and explained $11 \%$ of variance. Openness did not emerge as a significant predictor of emotional exhaustion. Depersonalization has also been found to be negatively and significantly correlated with openness $\left(\mathrm{r}=-.319^{*}, \mathrm{p}<.05\right)$. Regression analysis revealed that in male's sample openness emerged as a significant predictor of depersonalization and explained $10 \%$ of variance.

For details of results please see Figure1, Table 1, Table 2 and Table 3.

Table 1. Big Five correlate of burnout in females' sample ( $\mathrm{N}=50)$

\begin{tabular}{lccc}
\hline Variables & Emotional exhaustion & Depersonalization & Reduced personal accomplishment \\
\hline Openness & $-.292^{*}$ & $-.304^{*}$ & .047 \\
Conscientiousness & .014 & .152 & $-.351^{*}$ \\
Extraversion & $-.355^{*}$ & -.130 & .145 \\
Agreeableness & -.123 & $-.507^{* *}$ & .132 \\
Neuroticism & -.008 & -.099 & .098 \\
\hline
\end{tabular}

Table 2. Big Five correlate of burnout in males' sample ( $N=50)$

\begin{tabular}{lccc}
\hline Variables & Emotional exhaustion & Depersonalization & Reduced personal accomplishment \\
\hline Openness & $.287^{*}$ & $-.319^{*}$ & .184 \\
Conscientiousness & -.099 & -.170 & -.231 \\
Extraversion & $-.385^{* *}$ & .064 & -.141 \\
Agreeableness & -.139 & -.054 & -.058 \\
Neuroticism & -.061 & -.007 & -.177 \\
\hline
\end{tabular}



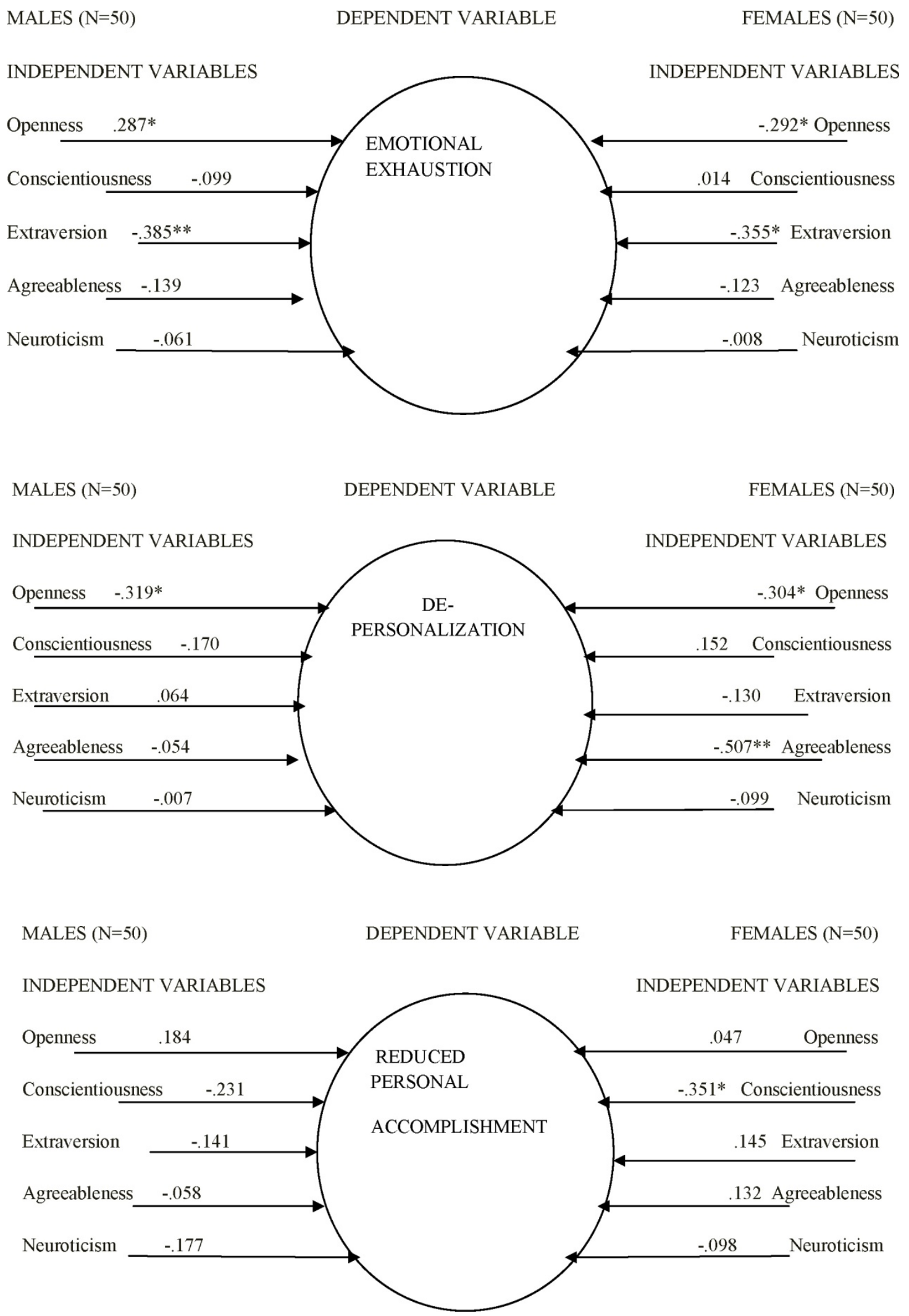

Figure 1. Correlations of personality variables with emotional exhaustion, depersonalization and reduced personal accomplishment for both the genders (Males and Females, $\mathrm{N}=50$ each) 
Table 3. Amount of variance explained by Personality variables in burnout (Emotional exhaustion, Depersonalization and Reduced personal accomplishment)

\begin{tabular}{|c|c|c|c|c|}
\hline BURNOUT DIMENSIONS $\longrightarrow$ & & $\begin{array}{l}\text { EMOTIONAL } \\
\text { EXHAUSTION }\end{array}$ & DEPERSONALIZATION & $\begin{array}{l}\text { REDUCED PERSONAL } \\
\text { ACCOMPLISHMENT }\end{array}$ \\
\hline \multicolumn{5}{|l|}{$\begin{array}{l}\text { THE BIG FIVE PERSONALITY } \\
\text { FACTORS }\end{array}$} \\
\hline \multirow[t]{2}{*}{ NEUROTICISM } & MALE & & & \\
\hline & FEMALE & & & $9 \%$ \\
\hline \multirow[t]{2}{*}{ EXTAVERSION } & MALE & $11 \%$ & & \\
\hline & FEMALE & $12 \%$ & & \\
\hline \multirow[t]{2}{*}{ OPENNESS } & MALE & & $10 \%$ & \\
\hline & FEMALE & & & \\
\hline \multirow[t]{2}{*}{ AGREEABLENESS } & MALE & & & \\
\hline & FEMALE & & $26 \%$ & \\
\hline \multirow[t]{2}{*}{ CONSCIENTIOUSNESS } & MALE & & & \\
\hline & FEMALE & & & $11 \%$ \\
\hline
\end{tabular}

\section{Discussion}

Emotional exhaustion, the first dimension of burnout, was found to be significantly and negatively correlated with openness in females' sample. People who score high on openness are adjustable and adaptable to new situations. They have good imagination and are quite creative. They tend to confront a stressful situation with a sense of curiosity and often tend to come up with new ideas about how to deal with a stressful situation (Watson \& Hubbard, 1996). According to Costa and McRae (1992), the curiosity of open-minded people leads them to try to learn something valuable from taxing and difficult experiences. So it can be expected that people high on this trait won't get emotionally exhausted easily by stressful situations. They would rather seek challenges to learn something new from those stressful situations. Openness may be associated with stress reduction because even a stressful situation is seen as less threatening by individuals who score high on this factor (Smith \& Williams, 1992). Lesser the threat evaluation of a situation, lesser will be the perceived stress. A possible outcome of lesser perceived stress is lesser emotional exhaustion. The females' sample, in the present study, seems to be using imaginative and flexible coping strategies and probably this is preventing them from being overstressed and emotionally exhausted. There are also some sex differences in conversational behavior. The stereotype of female talkativeness is actually considered a scientific fact by many. In the first printing of her book, neuropsychologist Brizendine reported, "A woman uses about 20000 words per day while a man uses about 7000 ". So by speaking and conversing more, women may be relieving themselves of stress by cathartic effect of speaking, expressing and conversing. This factor also contributes to less likelihood of emotional exhaustion. The finding related to females' sample above is consistent with many of the previous researches in the area. Storm and Rothmann (2003) did a study on pharmaceutical corporate employees and found that openness was negatively correlated with emotional exhaustion. In another study, Bakker, Van der Zee, Lewig and Dollard (2006) found a negative correlation between emotional exhaustion and openness among volunteer counselors. Similarly, investigating the association of burnout and personality traits of hotel managers, Zopiatis, Constanti and Pavlou (2010) also found a negative correlation between openness and emotional exhaustion.

On the contrary, emotional exhaustion was found to be significantly and positively correlated with openness for males' sample. This has not been found in many previous studies but only in few. According to some experts, a person who scores high on openness can be more experimenting and risk taking. They also tend to have a more liberal outlook in life (Atkinson, Atkinson, Smith, \& Bem, 1990). Sometimes they tend to get much more emotionally exhausted than people who are more conservative and conventional because they tend to take more risks while trying to contribute and give more to their helping jobs (which involve a lot of interpersonal interactions) and get in emotional agony and pain. 
Deary, Watson and Hogston (2003) did a longitudinal study of burnout in nursing students and found personality factors to be a significant determinant of burnout. Another finding was that that nurses with more open personalities were more likely to be emotionally exhausted. In another study with similar results, Lent (2010) studied the impact of work setting, demographic factors and personality factors on burnout of professional counselors and found that openness had positive correlation with emotional exhaustion.

With extraversion, emotional exhaustion was found to be significantly and negatively correlated for both males' and females' samples. This finding is similar to many of the previous researches done in the area. Extraverts are highly confident. They are active and dominant. They seek excitement. Full with positive emotions, they frequently get involved in intense personal interactions. People who score high in extraversion also show high level of optimism (Costa \& McRae, 1992). With their optimistic nature and positive attitude, they tend to focus on good and positive aspects and never (or rarely) dwell on negative side of any situation. The overall "positivity" and "nice and cheery" outlook of these people prevent them from panicking quickly. So it is not surprising that such people are less likely to feel as if their emotional energy has been drained out quickly when faced with chronic stress of work environment. Previous works done in the area have found similar results. In a study, Piedmont (1993) did a longitudinal analysis of burnout in healthcare settings and found that extraversion was negatively associated with emotional exhaustion. In another study, Michielsen, Willemsen, Croon, De Vries, and Van Heck (2004) attempted to determine the effect of personality and self-esteem on teachers' vulnerability to burnout and found that, among other things, extraversion was negatively associated with emotional exhaustion. Similarly, in a study of hospitality employees, Kim, Shin and Umbreit (2007) found a negative relationship between extraversion and emotional exhaustion. Also, in a study, Ang, Dhaliwal, Ayre, Uthaman, Fong, Tien, Zhou and Della (2016) studied personality and demographic factors associated with burnout among nurses and found that extraversion was one of the major determinants of high emotional exhaustion.

Depersonalization, another dimension of burnout, has been found to be significantly and negatively correlated with "openness" in both males' and females' samples. The finding above is consistent with findings of many previous researches. One of the ways in which depersonalization presents itself is through excessive use of technical jargon by healthcare professionals (Maslach \& Pines, 1977). Another way in which depersonalization gets displayed is by too much dependency on rules of bureaucracy (Daley, 1979). Depersonalization also gets exhibited by use of disrespectful, disapproving, insulting, rude, mean and/or abusive language while referring to clients (Cordes \& Doughtery, 1993). Many experts consider it just another dysfunctional coping mechanism. Those high in openness can cope with stress using humor or other creative ways and are less likely to use a dysfunctional coping mechanism such as depersonalization. So it can be expected that depersonalization will be negatively correlated with openness. In a study, exploring the relationship between personality and burnout among South African university students, Morgan and Bruin (2010) found that "openness" was negatively correlated to depersonalization. Similarly, Magnano, Paolillo and Barrano (2015) explored the relationship between personality and burnout in workers of helping professions. One of the findings of their study was that "openness" was negatively correlated with depersonalization. Also, Ghorpade, Lackritz, and Singh (2007) and Bakker et al. (2006) found a negative correlation between openness and burnout in their studies. Cañadas-De la Fuente, Vargas, San Luis, García, Cañadas and De la Fuente (2015) also found that depersonalization was negatively correlated with openness.

Depersonalization has also been found to be significantly and negatively correlated with agreeableness in females' sample. Depersonalization was also found to be negatively correlated with agreeableness in males' sample. Those who score high on agreeableness are gullible and have a sense of concern for happiness, health, welfare, etc., of others. They are not selfish. They care deeply about well-being of others. A highly agreeable person is soft at heart and has a good nature. She/he forgives easily. She/he is straightforward (Costa \& McCrae, 1992). People who show high scores on this dimension are polite, cooperative and have capacity to empathize with others. Polite, empathic and cooperative people are less likely to develop negative and cynical attitudes toward the recipients of one's service and hence are less likely to be depersonalized. Some previous work has found similar results as the results of the present study. For example, Piedmont (1993) found that agreeableness was negatively associated with depersonalization. Consistently, Deary et al. (1996), in their study of consultant doctors, reported that agreeableness is negatively related to depersonalization. Mills and Huebner (1998) studied personality characteristics, occupational stressors and burnout among school psychology practitioners and found that agreeableness showed a negative relationship with depersonalization. Similarly Zellars, Perrewe, and Hochwarter (2000) studied burnout in healthcare setting and found that agreeableness and depersonalization were negatively correlated. Cetin and Hazir (2012), in their study, also found that more agreeable participants had lesser level of depersonalization. 
Reduced personal accomplishment, the third dimension of burnout, was found to be significantly and negatively correlated with conscientiousness in females' sample. Reduced personal accomplishment was also found to be negatively associated with conscientiousness among males' sample. Conscientiousness is a dimension related to persistent effort towards goals. This is often reflective of an individual's need to achieve. Those who score high in conscientiousness are very motivated towards their goals. They are also able to plan their pursuit, venture or undertaking and, hence, are organized and diligent. Quite often they are self-disciplined and punctual (Costa \& McCrae, 1992). Punctuality and organization are significant work characteristics, and as such, high scores on conscientiousness predict success at work (Hogan R., Hogan J., \& Roberts, 1996). So it's understandable that conscientiousness will be negatively correlated with reduced personal accomplishment. Previous works in the area have given similar results. For example, Deary, Blenkin, Agius, Endler, Zealley and Wood (1996) studied job-related stress and personal achievement among consultant doctors and found that there was a positive relationship between conscientiousness and personal accomplishment. Also, Salgado (1997) investigated the relationship between the personality traits and job performance. The findings revealed that the factor of conscientiousness is one of the best determinants of job performance. Similarly, Takemura, Hasegawa, Tamura, Takishita, Matsuoka, Iwawaki and Yamanaka (2015) studied burnout syndrome and personality in Japanese nursing students and found that there was a positive relationship between conscientiousness and personal accomplishment.

\section{Implications}

The results of the study suggest that there are significant correlation between personality factors of the Big Five and burnout. Doctors scoring high in the personality dimensions of openness, conscientiousness, extraversion and agreeableness are associated with lower risk of developing burnout. One of the best implications of the study is the fact that the obtained results indicate that against known risks of developing burnout among doctors, certain personality traits can act as buffers or are at least less likely to be associated with burnout components. In counseling and training of doctors to better help them cope with stress and prevent burnout, doctors scoring very low in personality dimensions of openness, conscientiousness, extraversion and agreeableness should be given special attention. For such individuals (who are at greater risk for developing burnout), more specialized programs for improving their coping skills in dealing with stressful work situations and in reducing their negative emotional responses to such situations may be necessary. For example, low scorers on agreeableness dimension, could be encouraged to be more co-operative, forgiving and to keep a watch over their own thoughts, feelings and behavior so that they can keep a check on their own level of cynicism, etc. The findings of the present study also have implications for professionals from other professions such as teachers and lawyers. Teachers and lawyers scoring high in the personality dimensions of openness, conscientiousness, extraversion and agreeableness are more likely to be associated with lower risk of developing burnout and hence professionals scoring low in these dimensions need special assistance.

\section{References}

Ang, S. Y., Dhaliwal, S. S., Ayre, T. C., Uthman, T., Fong, K. Y., Tien, C. E., ... Della, P. (2016). Demographics and personality factors associated with burnout among nurses in a Singapore tertiary hospital. BioMed Research International, 2016. https://doi.org/10.1155/2016/6960184

Atkinson, R. L., Atkinson, R. C., Smith, E. A., \& Bem, D. J. (1990). Introduction to Psychology (10th ed.). San Diego, USA: Harcourt Brace Jovanovitch.

Azeem, S. M. (2013). Conscientiousness, neuroticism and burnout among healthcare employees. International Journal of Academic Research in Business and Social Sciences, 3, 467-477. https://doi.org/10.6007/IJARBSS/v3-i7/68

Bakker, A. B., Van Der Zee, K. I., Lewig, K. A., \& Dollard, M. F. (2006). The relationship between the Big Five personality factors and burnout: A study among volunteer counselors. Journal of Social Psychology, 146(1), 31-50. https://doi.org/10.3200/SOCP.146.1.31-50

Barrick, M. R., Mount, M. K., \& Strauss, J. P. (1993). Conscientiousness and performance of sales representatives: Test of the mediating effects of goal setting. Journal of Applied Psychology, 78, 715-722. https://doi.org/10.1037/0021-9010.78.5.715

Benet-Martinez, V., \& John, O. P. (1998). Los Cinco Grandes across cultures and ethnic groups: Multitrait-multimethod analyses of the Big Five in Spanish and English. Journal of Personality and Social Psychology, 75, 729-750. https://doi.org/10.1037/0022-3514.75.3.729

Brizendine, L. (2006). The Female Brain. New York: Morgan Road Books. 
Buhler, K. E., \& Land, T. (2003). Burnout and personality in intensive care: An empirical study. Hospital Topics: Research and Perspectives on Health Care, 81, 5-12. https://doi.org/10.1080/00185860309598028

Cañadas-De la Fuente, G. A., Vargas, C., San Luis, C., García, I., Cañadas, G. R., \& De la Fuente, E. I. (2015). Risk factors and prevalence of burnout syndrome in the nursing profession. International Journal of Nursing Studies, 52(1), 240-249. https://doi.org/10.1016/j.ijnurstu.2014.07.001

Celik, G. T., \& Oral, E. L. (2013). Burnout levels and personality traits-The case of Turkish architectural students. Creative Education, 4, 124-131. https://doi.org/10.4236/ce.2013.42018

Cetin, F., \& Hazir, K. (2012). The role of personality on the rise of burnout response in the organizational context. Business and Economics Research Journal, 3(2), 65-77.

Cordes, C. L., \& Dougherty, T. W. (1993). A review and an integration of research on job burnout. Academy of Management Review, 18(4), 621-656.

Costa, P. T. Jr., \& McCrae, R. R. (1992). Revised NEO Personality Inventory (NEO-PIR) and NEO Five Factor Inventory (NEO-FFI) professional manual. Odessa, Fl.: Psychological Assessment Resources.

Daley, M. R. (1979). Burnout: Smoldering problems in protective services. Social Work, 374-379.

Deary, I. J., Blenkin, H., Agius, R. M., Endler, N. S., Zealley, H., \& Wood, R. (1996). Models of job-related stress and personal achievement among consultant doctors. British Journal of Psychology, 87, 3-29. https://doi.org/10.1111/j.2044-8295.1996.tb02574.x

Deary, I. J., Watson, R., \& Hogston, R. (2003). A longitudinal cohort study of burnout and attrition in nursing students. Journal of Advanced Nursing, 43, 71-81. https://doi.org/10.1046/j.1365-2648.2003.02674.x

Ghorpade, J., Lackritz, J., \& Singh, G. (2007). Burnout and Personality: Evidence from academia. Journal of Career Assessment, 15, 240-256. https://doi.org/10.1177/1069072706298156

Hogan, R., Hogan, J., \& Roberts, B. W. (1996). Personality measurement and employment decisions: Questions and answers. American Psychologist, 51, 469-477. https://doi.org/10.1037/0003-066X.51.5.469

Judge, T. A., Higgins, C., Thoresen, C. J., \& Barrick, M. R. (1999). The Big Five personality traits, general mental ability, and career success across the life span. Personnel Psychology, 52, 621-652. https://doi.org/10.1111/j.1744-6570.1999.tb00174.x

Kim, J. H., Shin, H. K., \& Umbreit, T. W. (2007). Hotel job burnout: The role of personality characteristics. Hospitality Management, 26(2), 421-434. https://doi.org/10.1016/j.ijhm.2006.03.006

Kızılcı, S., Erdoğan, V., \& Sözen, E. (2012). The Influence of selected Personality and workplace features on burnout among nurse academics. The Turkish Online Journal of Educational Technology, 11(4), 307-314.

Kokkinos, C. M. (2007). Job stress, personality and burnout in primary school teachers. British Journal of Educational Psychology, 77(1), 222-243. https://doi.org/10.1348/000709905X90344

Lent, J. (2010). The impact of work setting, demographic factors, and personality factors on burnout of professional counselors (Doctoral Dissertation). University of Akron, Ohio, United States.

LePine, J. A., LePine, M., \& Jackson, C. L. (2004). Challenge and hindrance stress: Relationships with exhaustion, motivation to learn, and learning performance. Journal of Applied Psychology, 89, 883-891. https://doi.org/10.1037/0021-9010.89.5.883

Magnano, P., Paolillo, A., \& Barrano, C. (2015). Relationships between personality and burn-out: An empirical study with helping professions' workers. International Journal of Social Science and Humanities Research, 1, 9-10.

Marine, A., Ruotsalainen, J. H., Serra, C., \& Verbeek, J. H. (2006). Preventing occupational stress in healthcare workers. Cochrane Database of Systematic Reviews. https://doi.org/10.1002/14651858.CD002892.pub2

Maslach, C. (1982). Burnout: The cost of caring. New Jersey: Prentice-Hall.

Maslach, C., \& Leiter, M. P. (1997). The Truth About Burnout. San Francisco: Jossey-Bass.

Maslach, C., \& Pine, A. (1977). The burnout syndrome in the day care setting. Child Care Quarterly, 6, 100-113. https://doi.org/10.1007/BF01554696

Maslach, C., Jackson, S. E., \& Leiter, M. P. (1996). Maslach burnout inventory manual (3rd ed.). Palo Alto, CA: Consulting Psychologists Press. 
McMurray, J. E., Linzer, M., Konrad, T. R., Douglas, J., Shugerman, R., \& Nelson, K. (2000). The work lives of women physicians. Journal of General Internal Medicine, 15, 372-380.

McVicar, A. (2003). Workplace stress in nursing: A literature review. Journal of Advanced Nursing, 44, 633-642. https://doi.org/10.1046/j.0309-2402.2003.02853.x

Michielsen, H. J., Willemsen, T. M., Croon, M. A., De Vries, J., \& Van Heck, G. L. (2004). Determinants of general fatigue and Emotional exhaustion: A prospective study. Psychology and Health, 19, 223-235. https://doi.org/10.1080/08870440310001627135

Mills, L. B., \& Huebner, E. S. (1998). A prospective study of personality characteristics, occupational stressors, and burnout among school psychology practitioners. Journal of School Psychology, 36(1), 103-120. https://doi.org/10.1016/S0022-4405(97)00053-8

Morgan, B., \& Bruin, K. (2010). The relationship between the big five personality traits and burnout in South African university students. South African Journal of Psychology, 2, 182-191. https://doi.org/10.1177/008124631004000208

Peisah, C., Latif, E., Wilhelm, K., \& Williams, B. (2009). Secrets to psychological success: Why older doctors might have lower psychological distress and burnout than younger doctors. Aging \& Mental Health, 13, 300-307. https://doi.org/10.1080/13607860802459831

Peterson, U., Demerouti, E., Bergström, G., Samuelsson, M., Åsberg, M., \& Nygren, Å. (2008). Burnout and physical and mental health among Swedish healthcare workers. Journal of Advanced Nursing, 62(1), 84-95. https://doi.org/10.1111/j.1365-2648.2007.04580.x

Piedmont, L. R. (1993). A longitudinal analysis of burnout in health care setting: The role of personal dispositions. Journal of Personality Assessment, 61(3), 457-473. https://doi.org/10.1207/s15327752jpa6103_3

Salgado, J. F. (1997). The five-factor model of personality and job performance in the European Community. Journal of Applied Psychology, 82, 30-43. https://doi.org/10.1037/0021-9010.82.1.30

Sehlen, S., Vordermark, D., Schäfer, C., Herschbach, P., Bayerl, A., Pigorsch, S., ... Geinitz, H. (2009). Job stress and job satisfaction of physicians, radiographers, nurses and physicists working in radiotherapy: A multicenter analysis by the DEGRO Quality of Life Work Group. Radiation Oncology, 4(6), 1 Y9. https://doi.org/10.1186/1748-717X-4-6

Smith, T. W., \& Williams, P. G. (1992). Personality and health: Advantages and limitations of the five-factor model. Journal of Personality, 60, 395-423. https://doi.org/10.1111/j.1467-6494.1992.tb00978.x

Storm, K., \& Rothmann, S. (2003). The relationship between burnout, personality traits and coping strategies in a corporate pharmaceutical group. South African Journal of Industrial Psychology, 29, 35-42. https://doi.org/10.4102/sajip.v29i4.128

Takemura, K., Hasegawa, M., Tamura, S., Takishita, Y., Matsuoka, T., Yoko, I., \& Yamanaka, R. (2015). The association between burnout syndrome and personality in Japanese nursing students. International Journal of Recent Scientific Research, 6(7), 5545-5549.

Unaldi, I., Bardakci, M., Dolas, F., \& Arpaci, D. (2013). The relationship between occupational burnout and personality traits of Turkish EFL teachers. Journal of Education and Practice, 4, 86-98.

Von Känel, R., Bellingrath, S., \& Kudielka, B. M. (2008). Association between burnout and circulating levels of pro and anti-inflammatory cytokines in schoolteachers. Journal of Psychosomatic Research, 65(1), 51-59. https://doi.org/10.1016/j.jpsychores.2008.02.007

Watson, D., \& Hubbard, B. (1996). Adaptational style and dispositional structure: Coping in the context of the five-factor model. Journal of Personality, 64, 737-774. https://doi.org/10.1111/j.1467-6494.1996.tb00943.x

Williams, E. S., Manwell, L. B., Konrad, T. R., \& Linzer, M. (2007). The relationship of organizational culture, stress, satisfaction, and burnout with physician-reported error and suboptimal patient care: Results from the MEMO study. Health Care Management Review, 32(3), 203-212. https://doi.org/10.1097/01.HMR.0000281626.28363.59

Zellars, K. L., Perrewe, P. L., \& Hochwarter, W. A. (2000). Burnout in Health Care: The Role of the Five Factors of Personality. Journal of Applied Social Psychology, 30(8), 1570-1598. https://doi.org/10.1111/j.1559-1816.2000.tb02456.x 
Zopiatis, A., Constanti, P., \& Pavlou, I. (2010). Investigating the association of burnout and personality traits of hotel managers. International CHRIE Conference, Refereed Track, Paper 1.

\section{Statement}

The two authors' (Anita Sharma and Neelabh Kashyap) contribution to this article is equivalent.

\section{Copyrights}

Copyright for this article is retained by the author(s), with first publication rights granted to the journal.

This is an open-access article distributed under the terms and conditions of the Creative Commons Attribution license (http://creativecommons.org/licenses/by/4.0/). 